\title{
Visceral Arterial Ischemia, CTCAE
}

National Cancer Institute

\section{Source}

National Cancer Institute. Visceral Arterial Ischemia, CT CAE. NCI Thesaurus. Code

C143938.

A disorder characterized by a decrease in blood supply due to narrowing or blockage of a visceral (mesenteric) artery. 